\title{
Chemical Vapor Deposition of Cobalt Nitride and its Application as an Adhesion-Enhancing Layer for Advanced Copper Interconnects
}

\section{Citation}

Bhandari, Harish B., Jing Yang, Hoon Kim, Youbo Lin, Roy G. Gordon, Qing Min Qang, JeanSebastien Lehn, Huazhi Li, Deo Shenai. 2012. ECS Journal of Solid State Science and Technology 1(5): N79-N84.

\section{Published Version}

doi:10.1149/2.005205jss

\section{Permanent link}

http://nrs.harvard.edu/urn-3:HUL.InstRepos:9925419

\section{Terms of Use}

This article was downloaded from Harvard University's DASH repository, and is made available under the terms and conditions applicable to Other Posted Material, as set forth at http:// nrs.harvard.edu/urn-3:HUL.InstRepos:dash.current.terms-of-use\#LAA

\section{Share Your Story}

The Harvard community has made this article openly available.

Please share how this access benefits you. Submit a story.

\section{Accessibility}


Chemical Vapor Deposition of Cobalt Nitride and its Application as an Adhesion-Enhancing Layer for Advanced Copper Interconnects

Harish B. Bhandari, Jing Yang, Hoon Kim, Youbo Lin, Roy G. Gordon, Qing Min Wang, Jean-Sébastien M. Lehn, Huazhi Li and Deo Shenai

ECS J. Solid State Sci. Technol. 2012, Volume 1, Issue 5, Pages N79-N84. doi: 10.1149/2.005205jss

Email alerting service
Receive free email alerts when new articles cite this article - sign up in the box at the top right corner of the article or click here

To subscribe to ECS Journal of Solid State Science and Technology go to: http://jss.ecsdl.org/subscriptions 


\title{
Chemical Vapor Deposition of Cobalt Nitride and its Application as an Adhesion-Enhancing Layer for Advanced Copper Interconnects
}

\author{
Harish B. Bhandari, ${ }^{\text {a,b }}$ Jing Yang, ${ }^{a}$ Hoon Kim, ${ }^{\text {a,c }}$ Youbo Lin, ${ }^{\text {a,d }}$ Roy G. Gordon, ${ }^{\text {a, }, \text {, }}$ \\ Qing Min Wang, ${ }^{\mathrm{e}}$ Jean-Sébastien M. Lehn, ${ }^{\mathrm{e}}$ Huazhi Li, ${ }^{\mathrm{e}}$ and Deo Shenai ${ }^{\mathrm{e}}$ \\ ${ }^{a}$ Harvard University, Cambridge, Massachusetts, 02138, USA \\ ${ }^{b}$ RMD - Radiation Monitoring Devices, Inc, Watertown, Massachusetts, 02472, USA \\ ${ }^{c}$ Albany NanoTech, Globalfoundries, Albany, New York 12203, USA \\ ${ }^{d}$ IBM East Fishkill, Globalfoundries, Hopewell Junction, New York 12533, USA \\ ${ }^{e}$ Dow Electronic Materials, The Dow Chemical Company, North Andover, Massachusetts 01845, USA
}

\begin{abstract}
An interlayer of face centered cubic (fcc) $\mathrm{Co}_{4} \mathrm{~N}$ has demonstrated significant improvements in adhesion between copper and diffusion barrier layers. This fcc phase of $\mathrm{Co}_{4} \mathrm{~N}$ was prepared by chemical vapor deposition (CVD) using bis( $N$-tert-butyl- $N^{\prime}$-ethylpropionamidinato)cobalt(II) and a reactant mixture of $\mathrm{NH}_{3}$ and $\mathrm{H}_{2}$ at substrate temperatures from 100 to $180^{\circ} \mathrm{C}$. The $\mathrm{Co} / \mathrm{N}$ atomic ratio and the phase of cobalt nitride film can be modified by adjusting the ratio of $\mathrm{NH}_{3}$ and $\mathrm{H}_{2}$ in the gas feedstock. The cobalt nitride films prepared by CVD are smooth, highly conformal, and stable against intermixing with copper up to at least $400^{\circ} \mathrm{C}$. This fcc cobalt nitride material has very strong adhesion to copper due to the small lattice mismatch ( -1 to $2 \%$ ) between fcc-Co $\mathrm{Co}_{4} \mathrm{Nand}$ $\mathrm{fcc} \mathrm{Cu}$. Copper wires should be stabilized against failure by electromigration when fcc cobalt nitride interlayers are placed between the copper and surrounding diffusion barriers.
\end{abstract}

(C) 2012 The Electrochemical Society. [DOI: 10.1149/2.005205jss] All rights reserved.

Manuscript received July 13, 2012. Published September 5, 2012.

Cobalt thin films are used widely in the microelectronic industry for numerous applications. Co is used to form $\mathrm{CoSi}_{2}$ by $\mathrm{Co} / \mathrm{Si}$ interfacial reactions to make source, drain and gate electrodes for CMOS structures. Although NiSi offers lower resistivity, ${ }^{1}$ the greater thermodynamic stability of $\mathrm{CoSi}_{2}$ makes it more suitable for DRAM structures where high processing temperatures are required. Cobalt is also a leading candidate for capping copper lines to improve the interconnect reliability against failure by electromigration. ${ }^{2}$ It has also been shown that introduction of a thin Co interlayer between $\mathrm{Cu}$ and barriers such as TaN, WN or TiN increased adhesion at the interface, presumably thereby increasing the lifetime of the copper wires. ${ }^{3}$ Other applications of Co films include magnetic devices ${ }^{4}$ and nano-catalysts for carbon nanotube synthesis. ${ }^{5}$

As the feature sizes in integrated circuits shrink to smaller sizes, conventional techniques such as physical vapor deposition (PVD) may not provide adequate step coverage owing to their nonconformal deposition. The problem gets especially challenging for three-dimensional CMOS devices and very narrow copper interconnects. In this article we report the deposition of a novel material, cobalt nitride, using a conformal technique of chemical vapor deposition (CVD). We discuss its potential application as an adhesion-enhancing interlayer for advanced copper interconnect technology.

Copper has successfully replaced aluminum for ultra large-scale integration (ULSI) because of its low resistivity and superior resistance against electromigration. In the damascene structure, copper is deposited using electroplating due to its low cost, high throughput and via-filling capability. However, the electro-deposition of thick copper is initiated on a pre-existing tri-layer stack which consists of a thin and continuous $\mathrm{Cu}$, an adhesion promoter and a barrier. The current technology utilizes physical vapor deposition (PVD) to make $\mathrm{Cu}$ (seed)/Ta (adhesion)/TaN (barrier) in the damascene structure. The International Technology Roadmap for Semiconductors (ITRS) projects that as the features shrink, these multilayer stacks have to be thinner and more conformal to maintain effective interconnect resistivity while avoiding any pinholes. It is becoming increasingly challenging for PVD to meet all these requirements and therefore there is a need for a conformal deposition technique such as CVD or atomic layer deposition (ALD). Metal depositions using ALD have slower growth rates than their CVD counterparts and in most cases, longer deposition leads to rougher morphology due to agglomeration. CVD of $\mathrm{Cu}$ has been extensively studied because of its fast deposition rate compared to

*Electrochemical Society Active Member.

${ }^{\mathrm{z}}$ E-mail: gordon@ chemistry.harvard.edu
ALD and its ability to minimize agglomeration in a kinetically driven process. ${ }^{6}$ However, CVD $\mathrm{Cu}$ is known to exhibit weak adhesion to Ta-based adhesion/barrier layers due to the formation of Ta oxide or Ta fluoride during the CVD process. ${ }^{7}$ Ta's high affinity to oxygen and fluorine can extract these elements from a copper precursor during the CVD process. Trace amounts of oxygen or oxygen-containing impurities in the carrier gas can also oxidize the tantalum surface. The presence of an oxide or fluoride layer on Ta facilitates electromigration at the copper/oxide interface, because of the weaker adhesion. $\mathrm{Cu}$ can now be deposited by $\mathrm{ALD}^{8}$ or $\mathrm{CVD}^{9}$ from precursors that contain neither oxygen nor fluorine, thus providing a possible way to provide strong adhesion of CVD $\mathrm{Cu}$ to Ta. However, at present, there is no way to deposit conformal tantalum layers, either by CVD or by ALD. Thus alternative materials for adhesion layers have been sought.

Various studies have been conducted to examine different metals such as $\mathrm{Ru},{ }^{10,11} \mathrm{Pd},{ }^{12} \mathrm{Pt},{ }^{13} \mathrm{Rh},{ }^{13} \mathrm{Ir},{ }^{14} \mathrm{Ag},{ }^{15} \mathrm{Os}^{16}$ or $\mathrm{Co}^{17}$ as possible candidates for an adhesion layer to replace Ta. These more noble metals bind oxygen and fluorine less strongly than Ta does, so they are expected to adhere better to CVD Cu than Ta does. Recently Ru has received much attention and has been widely studied. ${ }^{11} \mathrm{Ru}$ is a stable metal with low resistivity $(7.4 \mu \Omega \cdot \mathrm{cm})$ and strong adhesion to $\mathrm{Cu}$, but $\mathrm{Ru}$ is expensive and in short supply, making it a poor choice for large-scale use.

There are reports suggesting that the adhesion energy at the interface between two metals is larger if their lattices match in size and structure. ${ }^{11,18,19}$ Hoon et al. ${ }^{18}$ have demonstrated that a smaller lattice mismatch of $\mathrm{Cu}$ with $\mathrm{Ru}$ compared to with Ta leads to a lower interface energy and enhanced adhesion of $\mathrm{Cu}$ onto $\mathrm{Ru}$. According to this mismatch principle, the strongest adhesion to copper should be found for a metal with the same face-centered cubic (fcc) structure and the same lattice constant as copper. The lattice misfits between $\mathrm{Cu}$ and $\mathrm{Co}, \mathrm{Co}_{4} \mathrm{~N}$ and $\mathrm{Ru}$ are summarized in Table I, which suggests that $\mathrm{Co}_{4} \mathrm{~N}$ has cobalt atoms arranged in the same fcc structure as $\mathrm{Cu}$ and with almost exactly the same lattice constant (mismatch only $-0.8 \%$ ). Therefore, $\mathrm{Co}_{4} \mathrm{~N}$ should have a strong adhesion to copper.

In this report we demonstrate successful CVD of cobalt nitride as an interlayer between CVD WN (barrier) and CVD Cu (seed), all of which is performed in a single CVD reactor without breaking the vacuum. The cobalt nitride exhibits the fcc $\mathrm{Co}_{4} \mathrm{~N}$ structure that closely matches the $\mathrm{Cu}$ lattice and hence demonstrates the expected strong adhesion to CVD copper grown on top of it. Strong adhesion is preserved during CVD also because the copper precursor contains no oxygen or fluorine that could contaminate the surface of the $\mathrm{Co}_{4} \mathrm{~N}$. During the CVD processes of various layers the carbon and hydrogen that accompany the metallorganic precursors are completely removed as 


\begin{tabular}{|c|c|c|c|}
\hline $\begin{array}{l}\text { Candidate } \\
\text { material }\end{array}$ & $\begin{array}{l}\text { Structure } \\
\text { type }\end{array}$ & $\begin{array}{l}\text { Lattice mismatch } \\
\text { with } \mathrm{Cu}\end{array}$ & $\begin{array}{l}\text { Lattice constant } \\
(\AA)\end{array}$ \\
\hline $\mathrm{Cu}$ & fcc & $0 \%$ & $\mathrm{a}=\mathrm{b}=\mathrm{c}=3.615$ \\
\hline $\mathrm{Co}_{4} \mathrm{~N}$ & $\mathrm{fcc}$ & $-0.8 \%$ & $\mathrm{a}=\mathrm{b}=\mathrm{c}=3.586$ \\
\hline$\alpha-\mathrm{Co}$ & $\mathrm{fcc}$ & $-1.9 \%$ & $\mathrm{a}=\mathrm{b}=\mathrm{c}=3.545$ \\
\hline$\varepsilon-\mathrm{Co}$ & hcp & $-2.0 \%$ & $2^{1 / 2} a=3.544$ \\
\hline $\mathrm{Ru}$ & hcp & $+5.9 \%$ & $2^{1 / 2} \mathrm{a}=3.827$ \\
\hline
\end{tabular}

vapor byproducts resulting in pure films. The CVD Cu grows epitaxially on all orientations of the polycrystalline $\mathrm{Co}_{4} \mathrm{~N}$ grains, as shown by high-resolution transmission electron microscopy (TEM). Such a CVD cobalt nitride can also be used to make conformal $\mathrm{CoSi}_{2} \cdot{ }^{20}$

\section{Experimental}

The chemical vapor deposition of $\mathrm{Co}_{\mathrm{x}} \mathrm{N}$ was carried out in a hot wall, tube-furnace reactor. The schematic of the CVD system is as shown in Figure 1. The substrate holder is a half cylinder made of aluminum which was inserted into a stainless steel reactor tube. A cartridge heater and a thermocouple (not shown) are embedded in the substrate holder in order to heat the substrate to a temperature higher than the reactor wall by $10-20^{\circ} \mathrm{C}$. This arrangement favors deposition of desired film on the substrate rather than the wall and is suitable for a CVD process with a thermally activated rate. The reactor pressure during deposition was controlled automatically by a throttle valve (MKS Instruments) located downstream to the substrate holder. The metal precursors were loaded in U-shaped bubblers and ultra high purity $\mathrm{N}_{2}$ was used as a carrier gas. The bubblers and their associated gas lines were plumbed inside ovens with suitable temperature set points for efficient vaporization and delivery of precursor vapors to the reactor tube. The gas flow rates were established using metalsealed mass flow controllers (MKS Instruments).

CVD of $\mathrm{Co}_{\mathrm{x}} \mathrm{N}$ was carried out from bis $\left(N\right.$-tert-butyl- $N^{\prime}$-ethylpropionamidinato)cobalt(II), $\mathrm{Co}\left[\mathrm{Bu}^{\mathrm{t}} \mathrm{NC}(\mathrm{Et}) \mathrm{NEt}\right]_{2}$, precursor. The synthesis of $\mathrm{Co}\left[\mathrm{Bu}{ }^{t} \mathrm{NC}(\mathrm{Et}) \mathrm{NEt}\right]_{2}$ has been described elsewhere. ${ }^{21}$ This Co precursor is a dark green liquid at room temperature with melting point of $-17^{\circ} \mathrm{C}$. The vapor pressure of this precursor may be approximated by $\log _{10}(\mathrm{P}$, torr $)=5.424-2151 / \mathrm{T}$, giving 0.14 torr at $70^{\circ} \mathrm{C}$ and 0.26 torr at $85^{\circ} \mathrm{C}$. Within this temperature range, the evaporation rate is about $0.1 \mathrm{nmol} \times \mathrm{min}^{-1} \times \mathrm{cm}^{-2}$ of liquid surface, as measured by isothermal thermogravimetric analysis (TGA). No decomposition

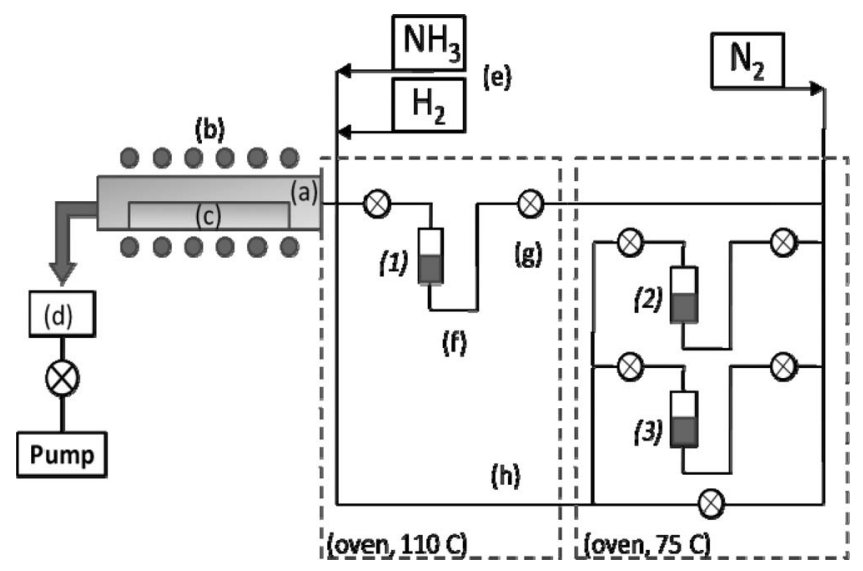

Figure 1. Schematic diagram of the CVD system. (a) deposition chamber; (b) furnace; (c) substrate holder; (d) throttle valve; (e) mass flow controllers; (f) bubbler; (g) pneumatically controlled valves; (h) bypass gas line; Precursors: (1) Cu precursor; (2) Co precursor; (3) W precursor.

\section{Table II. CVD conditions explored in this work.}

CVD Parameters

\section{Temperature:}

Pressure:

Co source temp:

$\mathrm{N}_{2}$ carrier gas:

Reactant Gas $\left(\mathrm{NH}_{3}+\mathrm{H}_{2}\right)$ :
Cobalt Nitride

$100-180^{\circ} \mathrm{C}$
$1-5$ torr
$70-85^{\circ} \mathrm{C}$
$60 \mathrm{sccm}$
$60+0,40+20,20+40$,
$10+50,0+60 \mathrm{sccm}$

was noted when bubblers were used in this temperature range over a period of several months. TGA with a linear temperature ramp of $10 \mathrm{~K} \mathrm{~min}^{-1}$ showed clean evaporation with no residue up to $200^{\circ} \mathrm{C}$, by which temperature the liquid had completely evaporated. ${ }^{21}$ This result showed that no significant decomposition occurs within time periods of minutes even at temperatures as high as $200^{\circ} \mathrm{C}$.

Another test of thermal stability was done by heating the neat liquid in contact with various surfaces: glass (presumably with little or no surface catalytic activity); oxidized stainless steel (to mimic a typical bubbler surface); and stainless steel from which the native oxide had been removed by acid etching. The viscosity of the precursor was also measured with flow tubes inside a glove box, in order to protect it from oxidation. Accelerated rate calorimetry (ARC) testing involves heating a closed sample at a series of increasing temperatures $10 \mathrm{~K}$ apart, with a dwell time of 50 minutes at each temperature. During this heating the pressure was measured to see if any gases are being generated by decomposition. If a significant pressure rise is detected, the dwell time is lengthened to see if the pressure rise is transient or if a self-sustained exotherm occurs.

The ranges of CVD conditions in which $\mathrm{Co}_{\mathrm{x}} \mathrm{N}$ films were deposited are shown in Table II. $\mathrm{NH}_{3}$ gas was used as the nitrogen source and $\mathrm{H}_{2}$ as the reducing agent. Although the ratio of $\mathrm{NH}_{3}$ to $\mathrm{H}_{2}$ gas flow was varied, the total flow rate of the mixture was always maintained at $60 \mathrm{sccm} .60 \mathrm{sccm}$ of $\mathrm{N}_{2}$ carrier gas passed through the bubbler to carry the precursor vapor into the deposition chamber. We assumed that an equilibrium vapor pressure of the Co precursor was achieved while the $\mathrm{N}_{2}$ bubbled up through about $10 \mathrm{~cm}$ of the liquid. A total pressure drop of 6.3 torr was estimated between the bubbler and the reactor tube, most of it arising from the pressures required to open the three spring-loaded check valves installed downstream to the bubbler. The check valves (not shown in Fig. 1) were used to separate multiple precursors installed in two ovens and to avoid back flow of vapor to cooler parts of the system. The high total pressure in the bubbler reduces the partial pressure of the precursors in the reactor, thereby limiting the overall growth rate and the step coverage inside features with high-aspect ratios. The estimated partial pressures for the reacting species are presented in Table III.

Table III. The effect of pressure drop in check valves in limiting the partial pressure of the Co precursor in the reactor.

Reactor

With 3

Design check valves check valve

Substrate Temperature:

Reactor wall temperature:

Reactor Pressure:

Co Precursor bubbler temp. $(\mathrm{P}=261 \mathrm{mtorr})$ :

$\mathrm{N}_{2}$ carrier gas:

Reactant Gas $\left(\mathrm{NH}_{3}+\mathrm{H}_{2}\right)$ :

Pressure Drop:

Bubbler Pressure:

$180^{\circ} \mathrm{C}$

Partial Pressures:

$\mathrm{P}_{\mathrm{N} 2}$ :

$\mathrm{P}_{\mathrm{NH} 3}$ :

$\mathrm{P}_{\mathrm{H} 2}$ :

$\mathrm{P}_{\mathrm{Co}}$ precursor:

Step Coverage:

Growth Rate (on $\mathrm{SiO}_{2}$ and WN): $160^{\circ} \mathrm{C}$

1 torr

$85^{\circ} \mathrm{C}$

$60 \mathrm{sccm}$ $20+40 \mathrm{sccm}$

6.3 torr $\quad 2.1$ torr

7.3 torr $\quad 3.1$ torr

0.49 torr $\quad 0.48$ torr

0.16 torr $\quad 0.16$ torr

0.33 torr $\quad 0.32$ torr

0.02 torr $\quad 0.04$ torr

$<10: 1 \quad>30: 1$

$\sim 0.5 \mathrm{~nm} / \mathrm{min} \sim 1 \mathrm{~nm} / \mathrm{min}$ 
CVD WN was deposited from bis(tertbutylimido)bis(dimethylamido)tungsten(VI) vaporized from a bubbler at $85^{\circ} \mathrm{C}$ and $\mathrm{NH}_{3}$ gas. The deposition conditions for $\mathrm{WN}$ were $390^{\circ} \mathrm{C}$ substrate temperature and 1 torr total pressure. The $\mathrm{N}_{2}$ carrier gas and $\mathrm{NH}_{3}$ flow rates were both set at $20 \mathrm{sccm}$. Cu metal or $\mathrm{CuON}$ was deposited from ( $N, N^{\prime}$-di-sec-butylacetamidinato)copper (I). For $\mathrm{Cu}$ deposition, $40 \mathrm{sccm}$ of $\mathrm{H}_{2}$ was used as the reducing agent and $40 \mathrm{sccm}$ of $\mathrm{N}_{2}$ was bubbled through the molten precursor at $95^{\circ} \mathrm{C}$. The $\mathrm{Cu}$ deposition was carried out at $180^{\circ} \mathrm{C}$ and 1 torr total pressure. An alternate route adopted to make smoother $\mathrm{Cu}$ films was to deposit $\mathrm{CuON}$ and reduce it after deposition at room temperature by hydrogen plasma. This process is discussed in detail elsewhere. ${ }^{6}$ Multilayer films were deposited without air break in order to prevent any oxidation of the films.

Substrates used in these experiments were $300 \mathrm{~nm}$ of thermally oxidized $\mathrm{SiO}_{2}$ supported on $\mathrm{Si}$ wafers. Before deposition, the substrates were exposed to a mercury UV lamp in air for $10 \mathrm{~min}$ to remove any organic contamination. The substrates were then dipped briefly in 5\% $\mathrm{HF}$ solution and rinsed in distilled water to expose fresh oxide surface by etching 20-30 nm of $\mathrm{SiO}_{2}$.

The surface morphologies of the films were characterized by an atomic force microscope (AFM, Asylum MFP-3D). The thicknesses of smoother films were measured by X-ray reflection (XRR, Scintag XDS 2000). For metals with rough surfaces, the films were patterned into stripes using photolithography and etching techniques, and the resulting thickness profiles were measured using AFM. The film composition and density were measured using $2 \mathrm{Mev} \mathrm{He}^{+}$Rutherford backscattering spectroscopy (RBS). The areal density of individual elements was determined by using a reference of Harwell Bi standard ${ }^{22}$ and by using a glassy carbon substrate. The phases of as-deposited films were evaluated by electron diffraction in a transmission electron microscope (JEOL, JEL2010), using as substrates a 50nm thick silicon nitride membrane suspended in a $3 \mathrm{~mm}$ Si wafer (TEM grid, Ted Pella.) Cross-section electron imaging of thin films was carried using TEM (JEOL 2100) and SEM (Zeiss Supra55VP) to study epitaxy and step coverage, respectively, of as-deposited thin films. The sheet resistance was measured by a four point probe station (Miller Design \& Equipment, FPP-500). The atomic concentrations of elements were analyzed by X-ray photoelectron spectroscopy (XPS, ESCA SSX-100.) The interfacial adhesion energies were evaluated by the four-point bend test, as described elsewhere. ${ }^{23}$

\section{Results and Discussion}

Properties of the liquid cobalt precursor- - Some additional properties of the cobalt precursor were measured. The viscosity as a function of temperature is given by $\ln \mu(\mathrm{cP})=3365.5 / \mathrm{T}(\mathrm{K})-8.1694$ and plotted in Fig. 2. Within the range of bubbler temperatures used, 70 to $85^{\circ} \mathrm{C}$, the viscosity is low, just 3 to 5 times that of water. Thus bubbling is not impeded by the viscosity of this precursor.

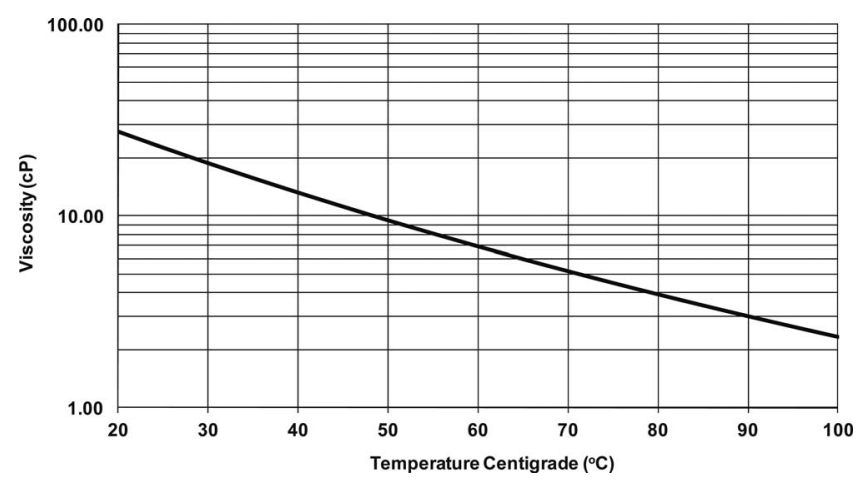

Figure 2. Viscosity of the cobalt precursor as a function of temperature.

\section{Table IV. Composition of cobalt nitride films by RBS, the} corresponding crystal phase, and the electrical resistivity.

\begin{tabular}{lllll}
$\begin{array}{l}\mathrm{NH}_{3} \\
\mathrm{sccm}\end{array}$ & $\begin{array}{l}\mathrm{H}_{2} \\
\mathrm{sccm}\end{array}$ & $\mathrm{Co}_{\mathrm{x}} \mathrm{N}_{\mathrm{y}}$ & Phase & $\begin{array}{l}\text { Resitivity } \\
(\mu \Omega \mathrm{cm})\end{array}$ \\
\hline 60 & 0 & $\mathrm{x}=2.3, \mathrm{y}=1.0$ & $\mathrm{Co}_{3} \mathrm{~N}, \mathrm{hcp}$ & $\sim 180$ \\
40 & 20 & $\mathrm{x}=3.8, \mathrm{y}=1.0$ & $\mathrm{Co}_{4} \mathrm{~N}, \mathrm{fcc}$ & $\sim 100$ \\
20 & 40 & $\mathrm{x}=4.4, \mathrm{y}=1.0$ & $\mathrm{Co}_{4} \mathrm{~N}, \mathrm{fcc}$ & $\sim 100$ \\
10 & 50 & $\mathrm{x}=6.9, \mathrm{y}=1.0$ & $\mathrm{Co}_{4} \mathrm{~N}, \mathrm{fcc}$ & $\sim 100$
\end{tabular}

Heating the neat precursor at $120^{\circ} \mathrm{C}$ in contact with glass, etched stainless steel or oxidized stainless steel for 60 hours did not generate any diamagnetic decomposition products in the NMR spectrum, indicating that thermal stability is not compromised by contact with these surfaces. An ARC test of stability was carried out. Slow, nonsustaining, transient exotherms were observed at 180,210 , and $219^{\circ} \mathrm{C}$. This test shows that little or no decomposition takes place at temperatures below $180^{\circ} \mathrm{C}$ over periods of hours. These thermal stability tests have important implications for the vaporization of this cobalt precursor in a direct liquid injection (DLI) system. ${ }^{24}$ In such a system, vaporization takes place within seconds, so that temperatures up to about $180^{\circ} \mathrm{C}$ could be used without significant decomposition of the precursor. Thus much higher vapor pressures can be produced in a DLI system than in a traditional bubbler. Much higher precursor partial pressures translates into the ability to coat much narrower features conformally. ${ }^{25}$

Chemical vapor deposition of $\mathrm{Co}_{x} \mathrm{~N}-\mathrm{C} \mathrm{Co}_{\mathrm{x}} \mathrm{N}$ films were deposited without an air-break on freshly-deposited $\mathrm{WN}$ in order to increase the adhesion energy of the films to substrates. Table IV shows RBS data for the composition of $\mathrm{Co}_{\mathrm{x}} \mathrm{N}$ films deposited at $180^{\circ} \mathrm{C}$ with various feed rates of $\mathrm{NH}_{3}$ and $\mathrm{H}_{2}$. The area density of nitrogen atoms in $\mathrm{Co}_{x} \mathrm{~N}$ was found by subtracting the area density of $\mathrm{N}$ in control samples of WN from the total number of $\mathrm{N}$ atoms per unit area detected by RBS in $\mathrm{Co}_{\mathrm{x}} \mathrm{N} / \mathrm{WN} / \mathrm{C}$. It is clear that $\mathrm{N}$ was incorporated into the asdeposited films only when $\mathrm{NH}_{3}$ was introduced, irrespective of its flow rate. All of the films show metallic conduction, with resistivity increasing with nitrogen content.

When $\mathrm{Co}_{\mathrm{x}} \mathrm{N}$ was deposited with just $\mathrm{NH}_{3}$ and no $\mathrm{H}_{2}$ gas, a composition $\mathrm{Co}_{2}{ }_{3} \mathrm{~N}$ was obtained. Figure 3 shows an electron diffraction pattern for a $\mathrm{Co}_{2.3} \mathrm{~N}$ film that corresponds to a $\mathrm{Co}_{3} \mathrm{~N}$ phase with a hexagonal close packed (hcp) structure. The only phase that resulted from $\mathrm{NH}_{3}$ alone as a co-reactant is the hcp $\left(\mathrm{Co}_{3} \mathrm{~N}\right)$ phase.

When $\mathrm{H}_{2}$ was introduced along with $\mathrm{NH}_{3}$ in different proportions, while maintaining the total flow rate of the two gases at $60 \mathrm{sccm}$, the as-deposited $\mathrm{Co}_{x} \mathrm{~N}$ films became richer in cobalt $(\mathrm{x}>2.3)$. Co precursor and $\mathrm{H}_{2}$ gas alone (no $\mathrm{NH}_{3}$ ) showed no reactivity at $180^{\circ} \mathrm{C}$ because no film growth was detected at that temperature. Thus $\mathrm{H}_{2}$ acts as a reducing agent during some stage of the reaction of the Co precursor with $\mathrm{NH}_{3}$ at $180^{\circ} \mathrm{C}$ even though it shows no direct reactivity with the Co precursor itself. The $\mathrm{Co} / \mathrm{N}$ atomic ratio increases as the $\mathrm{H}_{2} / \mathrm{NH}_{3}$ feed-ratio is increased.

These cobalt-rich films exhibit a fcc structure as shown in Figure 3 for the $\mathrm{NH}_{3} / \mathrm{H}_{2}=20 / 40 \mathrm{sccm}$ condition. A fcc $\mathrm{Co}_{4} \mathrm{~N}$ phase has been reported by other groups ${ }^{26,27}$ using sputtering. This is the first report of $\mathrm{Co}_{4} \mathrm{~N}$ material with the fcc phase prepared using CVD. The crystal geometry of the $\mathrm{Co}_{4} \mathrm{~N}$ phase can be considered to be made of $\mathrm{Co}$ atoms placed in a fcc lattice and a nitrogen atom trapped interstitially in the center of a unit cell. As a result, the introduction of $\mathrm{N}$ atoms should show expansion from the fcc Co lattice $(\mathrm{a}=3.545 \AA$ ). Theoretical studies of the $\mathrm{Co}_{4} \mathrm{~N}$ phase ${ }^{27}$ have shown that lattice expands as a function of interstitial nitrogen trapped per unit cell. Therefore it might be possible to adjust the lattice parameter of $\mathrm{Co}_{4} \mathrm{~N}$ experimentally by controlling the amount of nitrogen in the film. The polycrystalline $\mathrm{Co}_{4} \mathrm{~N}$ films have a relatively smooth morphology even when deposited on $\mathrm{SiO}_{2}$ without WN underneath. The AFM image shown in Fig. 4a for a $20 \mathrm{~nm} \mathrm{Co} \mathrm{C}_{4} \mathrm{~N}$ film has a root-mean-square (RMS) surface roughness 


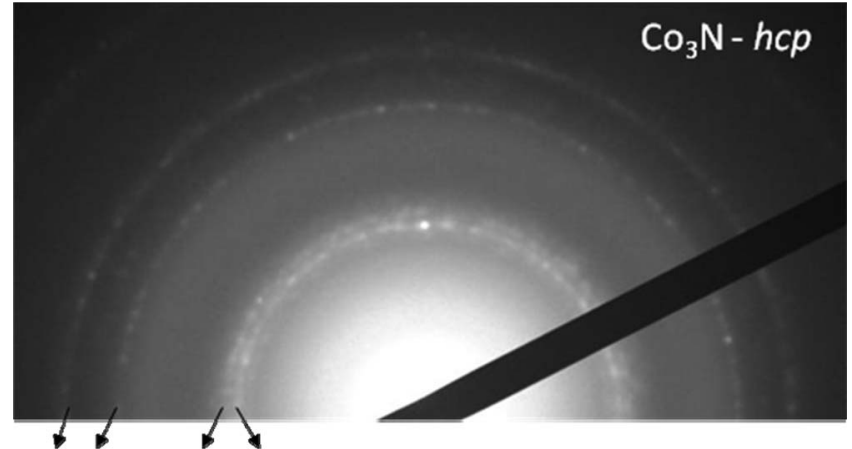
(d) (c)
(b) (a)
(a) (b) (c) (d')

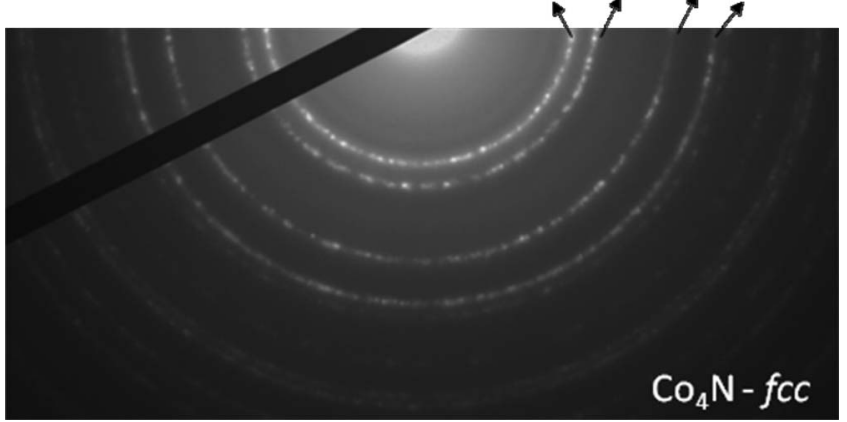

Figure 3. Electron diffraction patterns of polycrystalline $\mathrm{Co}_{3} \mathrm{~N}$ (a) $\langle 002\rangle$, (b) $\langle 101\rangle$, (c) $\langle 103\rangle$, (d) $\langle 201\rangle$ and $\mathrm{Co}_{4} \mathrm{~N}\left(\mathrm{a}^{\prime}\right)\langle 111\rangle,\left(\mathrm{b}^{\prime}\right)\langle 200\rangle,\left(\mathrm{c}^{\prime}\right)\langle 220\rangle$, $\left(d^{\prime}\right)\langle 311\rangle$.

of $1.3 \mathrm{~nm}$. In comparison, the AFM image shown in Fig. 4b showed CVD Co films of the same thickness 20nm deposited at a higher temperature $\left(240^{\circ} \mathrm{C}\right)$ with $\mathrm{H}_{2}$ as the only co-reactant are rougher (RMS roughness $=2.7 \mathrm{~nm})$.

Hetero-epitaxial relation between $\mathrm{Co}_{4} \mathrm{~N}$ and $\mathrm{Cu}$. - During the processing of copper interconnects, it is critical for $\mathrm{Cu}$ to adhere strongly to the underlying barrier material. The minimum adhesion energy recommended between $\mathrm{Cu}$ and the barrier material in order to survive the chemical mechanical planarization (CMP) is $5 \mathrm{~J} \times \mathrm{m}^{-2} \cdot{ }^{28}$ Amorphous WN is a well-studied barrier material for copper interconnects application but exhibits poor adhesion with CVD copper $\left(<2 \mathrm{~J} \times \mathrm{m}^{-2}\right) .^{3}$ In order to improve adhesion between $\mathrm{Cu}$ and $\mathrm{WN}$, an interlayer of

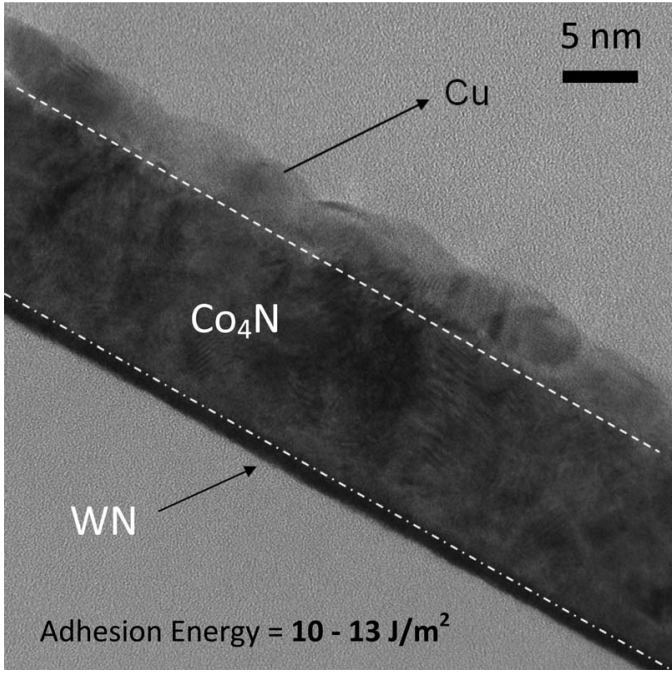

Figure 5. Cross-sectional TEM of $\mathrm{SiO}_{2} / \mathrm{WN} / \mathrm{Co}_{4} \mathrm{~N} / \mathrm{Cu}$.

$\mathrm{CO}_{4} \mathrm{~N}$ was tested. A stack of $\mathrm{CVD} \mathrm{Cu} / \mathrm{Co}_{4} \mathrm{~N} / \mathrm{WN}$ was deposited on $\mathrm{SiO}_{2} / \mathrm{Si}$ without breaking the vacuum. Fig. 5 shows the TEM cross section of the as-deposited film stack with sharp interfaces between the film stacks. The four-point bend test evaluation of the stack revealed adhesion energy of $10-13 \mathrm{~J} \times \mathrm{m}^{-2}$ between $\mathrm{Cu}$ and $\mathrm{Co}_{4} \mathrm{~N}$, which is stronger than the reported adhesion energy $6 \mathrm{~J} \times \mathrm{m}^{-2}$ of $\mathrm{Ru}$ glue layer. ${ }^{11}$ The high resolution TEM image (Fig. 5) shows that $\mathrm{Cu}$ grew epitaxially on the $\mathrm{Co}_{4} \mathrm{~N}$. The lattice spacing seen in Figure 6 matches the $\langle 111\rangle$ planes. The hetero-epitaxial relation between the two poly crystalline metals was discontinuous along the interface but was sufficient to promote strong adhesion.

The lattice parameters of $\mathrm{Co}_{4} \mathrm{~N}$ films with different amounts of nitrogen were evaluated by carrying out selected area electron diffraction (SAD) on thin films deposited on $\mathrm{Si}_{3} \mathrm{~N}_{4}$ TEM grids. Measurement of absolute lattice parameters from SAD diffraction patterns involved careful elimination of the instrumental errors. $\mathrm{Cu}$ was deposited on top of $\mathrm{Co}_{4} \mathrm{~N}$ film to form a $\mathrm{Cu} / \mathrm{Co}_{4} \mathrm{~N}$ stack, where the lattice parameter of $\mathrm{Cu}(\mathrm{a}=3.615 \AA)$ served as an internal standard. For comparison, copper was also deposited directly on the TEM grids. Fig. 7 shows the comparison of diffraction patterns from $\mathrm{Cu} / \mathrm{Co}_{4} \mathrm{~N}$ stack, $\mathrm{Cu}$ and $\mathrm{Co}_{4} \mathrm{~N}$ on TEM grids. The diffraction pattern on all three samples show three major rings that correspond to the $\langle 111\rangle,\langle 200\rangle,\langle 220\rangle$ and $\langle 311\rangle$ (a)

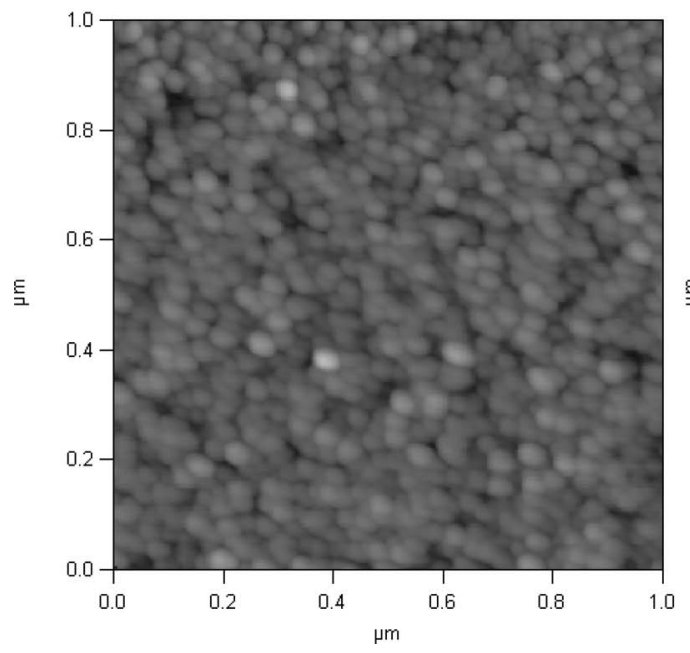

(b)

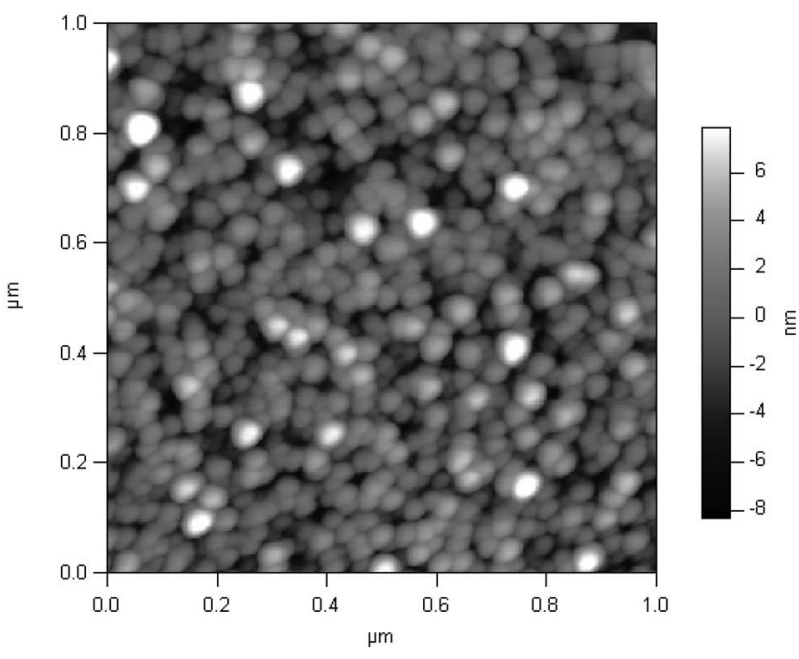

Figure 4. AFM images of (a) an Co4N film $20 \mathrm{~nm}$ thick, RMS roughness $=1.3 \mathrm{~nm}$; (b) a Co film $20 \mathrm{~nm}$ thick, RMS roughness $2.7 \mathrm{~nm}$. 


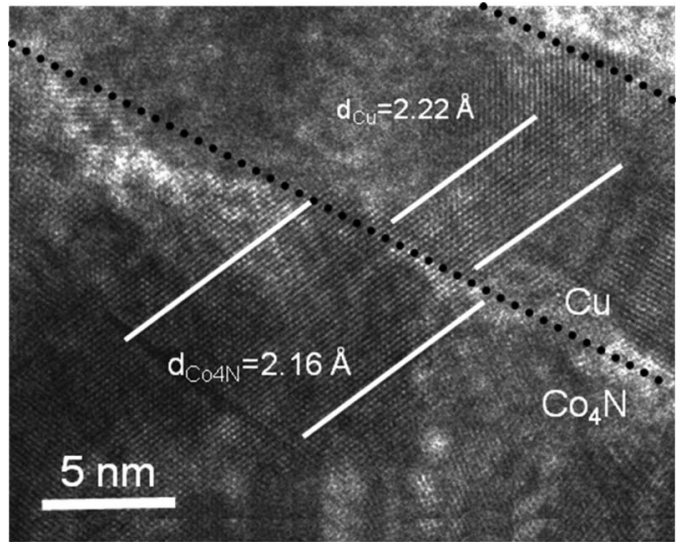

Figure 6. High-resolution cross-sectional TEM of the $\mathrm{Co}_{4} \mathrm{~N} / \mathrm{Cu}$ interface showing the epitaxial relation between the materials.

planes of fcc lattice. It is especially convincing that the diffraction signals from the bi-layer stack of $\mathrm{Co}_{4} \mathrm{~N}$ and $\mathrm{Cu}$ closely overlap with each other. This re-confirms the close match between the $\mathrm{Cu}$ and $\mathrm{Co}_{4} \mathrm{~N}$ lattice parameters, because both films are exactly the same distance from the detector. The only diffraction ring that does not show any overlap is that of the $\mathrm{Cu}_{2} \mathrm{O}$ along with the $\mathrm{Cu}$ sample, resulting from surface oxidation of copper. The diffraction rings from the $\mathrm{Cu} / \mathrm{Co}_{4} \mathrm{~N}$ film stack were carefully resolved to measure the lattice parameter of $\mathrm{Co}_{4} \mathrm{~N}$ using $\mathrm{Cu}$ as the internal standard. The resulting lattice parameters of the $\mathrm{Co}_{4} \mathrm{~N}$ are 1 to $2 \%$ smaller than $\mathrm{Cu}$, as expected from the literature values of the lattice constants of bulk single crystals. The precision of these values was not high enough to resolve any variation of the lattice constant of $\mathrm{Co}_{4} \mathrm{~N}$ with variations in the nitrogen content.

$\mathrm{Cu} / \mathrm{Co}_{4} \mathrm{~N}$ bilayers were also deposited on thin $\mathrm{Si}_{3} \mathrm{~N}_{4}$ TEM grids. Plane-view TEM pictures this film stack in Fig. 8 a show the grain size and nucleation density of copper on $\mathrm{Co}_{4} \mathrm{~N}$. For comparison, Fig. $8 \mathrm{~b}$ shows a CVD $\mathrm{Cu}$ film grown under the same conditions on a thin Co layer. The $\mathrm{Cu}$ grains are larger on the $\mathrm{Co}_{4} \mathrm{~N}$ substrate than on the Co substrate. Larger grains should translate into higher electrical conductivity.

Thermal stability of $\mathrm{Cu} / \mathrm{Co}_{4} \mathrm{~N}$ structure.- The thermal stability of the interface between $\mathrm{Co}_{4} \mathrm{~N}$ and $\mathrm{Cu}$ is crucial in keeping the resistivity of the $\mathrm{Cu}$ wires low. The thermal stability can be determined by annealing a stack containing the interface. A stack of $\mathrm{Cu} / \mathrm{Co}_{4} \mathrm{~N} / \mathrm{WN}$ was deposited on $\mathrm{SiO}_{2} / \mathrm{Si}$ using CVD. A $90 \mathrm{~nm}$ thick $\mathrm{Cu}$ was sputtered on top of the $10 \mathrm{~nm} \mathrm{Cu}$ to avoid agglomeration of free surface of $\mathrm{Cu}$. The stack was then annealed in forming gas $\left(\mathrm{N}_{2} / \mathrm{H}_{2}: 95 / 5 \mathrm{vol} \%\right)$ for $30 \mathrm{~min}$ at $400^{\circ} \mathrm{C}$. The sheet resistances of the film before and after

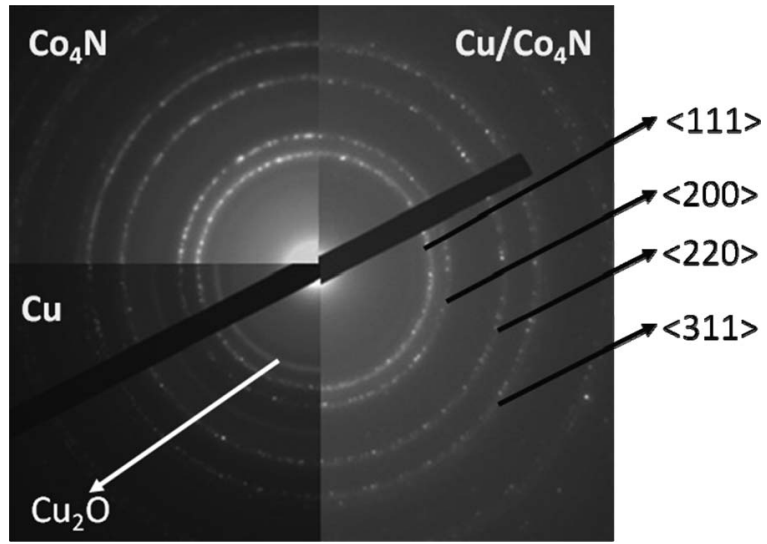

Figure 7. Electron diffraction patterns of a single layer of $\mathrm{Co}_{4} \mathrm{~N}$ (upper left), a bilayer film of $\mathrm{Cu} / \mathrm{Co}_{4} \mathrm{~N}$ (right side), and an oxidized $\mathrm{Cu}$ film (lower left). (a)

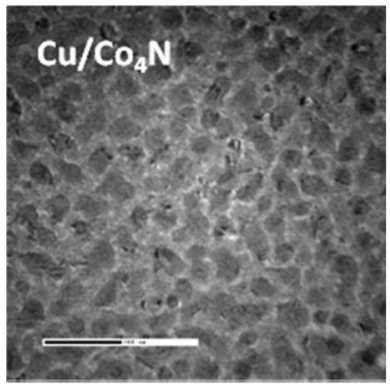

(b)

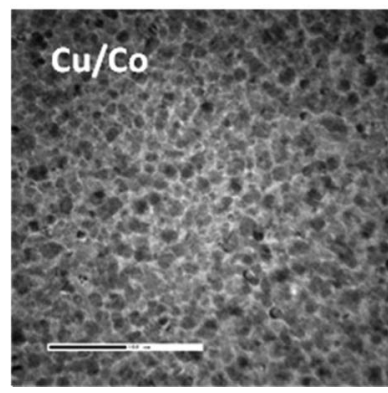

Figure 8. Comparison of $\mathrm{Cu}$ nucleation on (a) $\mathrm{Co}_{4} \mathrm{~N}$ and (b) $\mathrm{Co}$ underlayers. The average $\mathrm{Cu}$ grain size on $\mathrm{Co}$ is $\sim 19 \mathrm{~nm}$, whereas the grain size on $\mathrm{Co}_{4} \mathrm{~N}$ is $\sim 38 \mathrm{~nm}$.

the annealing step were $0.33 \mathrm{ohms} / \mathrm{sq}$ and $0.28 \mathrm{ohms} / \mathrm{sq}$, respectively. Post-annealing of this PVD Cu/ CVD Cu/Co ${ }_{4} \mathrm{~N} / \mathrm{WN}$ stack in $\mathrm{N}_{2}$ for $30 \mathrm{~min}$ at $400^{\circ} \mathrm{C}$ showed a decrease in the sheet resistance as well. The sheet resistances of the film stack before and after the annealing were $0.33 \mathrm{ohm} / \mathrm{sq}$ and $0.27 \mathrm{ohm} / \mathrm{sq}$. The sheet resistance of the $\mathrm{Cu}$ would have increased sharply if there were any migration of $\mathrm{Co}, \mathrm{N}$ or $\mathrm{Co}-\mathrm{N}$ species into the bulk of $\mathrm{Cu}$. The lowering of the sheet resistance indicates re-crystallization of $\mathrm{Cu}$, and an overall stability of the $\mathrm{Co}_{4} \mathrm{~N}$ and $\mathrm{Cu}$ interface.

Step coverage of $\mathrm{Co}_{4} \mathrm{~N}$.- The step coverage of $\mathrm{CVD} \mathrm{Co}_{4} \mathrm{~N}$ was tested by depositing film on a silicon substrate with holes having an aspect ratio of 30:1 with a diameter $336 \mathrm{~nm}$. The CVD conditions tested are tabulated in Table III. In the initial design of the system, there were 3 check valves between the cobalt bubbler and the reactor tube. The $\mathrm{Co}_{4} \mathrm{~N}$ deposition with three check valves in the system had low step coverage, even with aspect ratio lower than 10:1, the step coverage was not satisfactory. After removal of two check valves, it is found that step coverage on structures with aspect ratio of 30:1 is achieved with only a $20 \%$ reduction in film thickness on the bottom of
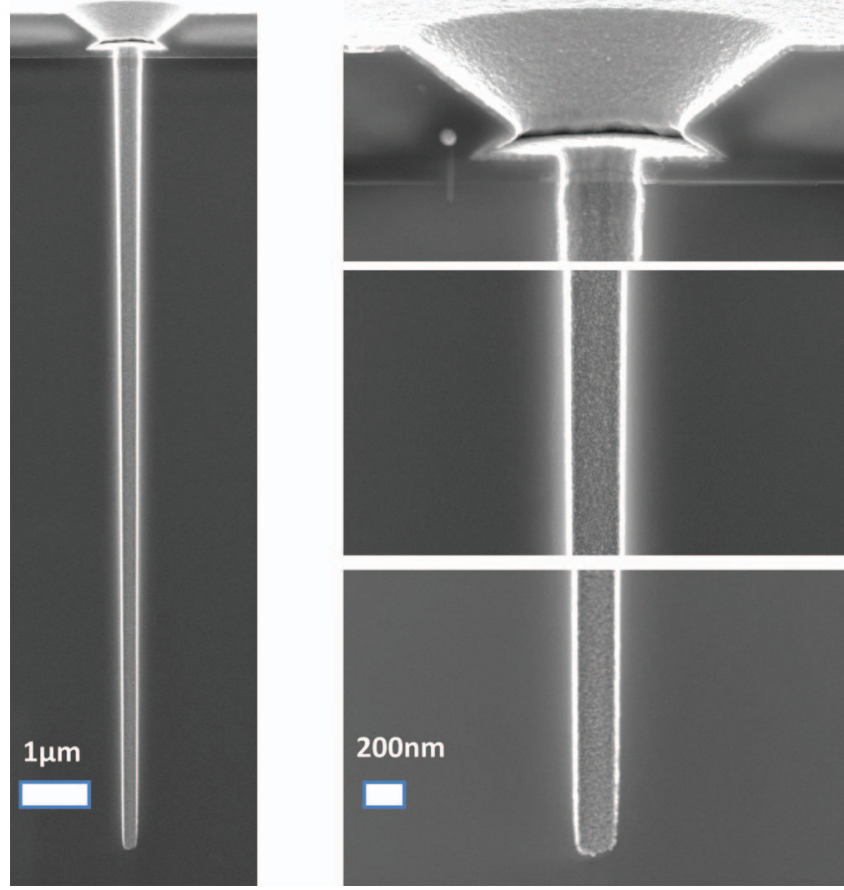

Figure 9. Cross-sectional SEM of a $\mathrm{Co}_{4} \mathrm{~N}$ film inside a narrow hole with an aspect ratio of about 30:1 
the hole $(\sim 23.5 \mathrm{~nm})$ compared with the top of the hole $(\sim 30 \mathrm{~nm})$. The step coverage tends to be poor when the CVD reaction is operating in transport-limited conditions of low partial pressure of the precursor inside the reactor and high surface reaction rate. Table III presents the partial pressures of different gases before and after removal of check valves. After the removal of two check valves, the partial pressure of cobalt precursor is 0.04 torr compared to 0.02 torr before the system optimization. The growth rate of the cobalt nitride film increased to $1 \mathrm{~nm} / \mathrm{min}$ from $0.5 \mathrm{~nm} / \mathrm{min}$. Fig. 9 shows an SEM image of nearly conformal deposition of $\mathrm{Co}_{4} \mathrm{~N}$ down to an aspect ratio of $30: 1$ in a hole. The overall step coverage can be improved by eliminating the back pressure from the check valves, increasing the vaporization temperature of the Co bubbler or by using DLI to make higher partial pressures of the precursor vapor. ${ }^{25}$

\section{Conclusions}

In this article we report Chemical Vapor Deposition synthesis of smooth, continuous and conformal $\mathrm{Co}_{4} \mathrm{~N}$ thin films using a cobalt amidinate, $\mathrm{Co}\left[\mathrm{Bu}^{\mathrm{t}} \mathrm{NC}(\mathrm{Et}) \mathrm{NEt}\right]_{2}$, as the cobalt source and a combination of $\mathrm{NH}_{3}$ and $\mathrm{H}_{2}$ gases. Although $\mathrm{H}_{2}$ shows no reactivity with the Co precursor at $180^{\circ} \mathrm{C}$, it stabilizes $\mathrm{Co}_{4} \mathrm{~N}$ into a face centered cubic structure in the presence of $\mathrm{NH}_{3}$ feed. In the absence of $\mathrm{H}_{2}$, the reaction between Co precursor and $\mathrm{NH}_{3}$ yields the $\mathrm{Co}_{3} \mathrm{~N}$ phase, which has a hexagonal close packed structure. The fcc structure of the $\mathrm{Co}_{4} \mathrm{~N}$ phase exhibits low $(-1 \%)$ mismatch with that of $\mathrm{Cu}$ and therefore shows a strong bonding (adhesion energy: 10-13 Joules $\mathrm{m}^{-2}$ ) at the $\mathrm{Co}_{4} \mathrm{~N} / \mathrm{Cu}$ interface. The stability of the interface was tested up to $400^{\circ} \mathrm{C}$ with no evidence of intermixing. Thus $\mathrm{Co}_{4} \mathrm{~N}$, which has a fcc structure, is a good choice for an adhesion-promoting under-layer for conformal methods of forming the $\mathrm{Cu}$ seed layers for advanced copper interconnects.

\section{Acknowledgment}

This work was performed in part at the Center for Nanoscale Systems (CNS) at Harvard University, a member of the National Nanotechnology Infrastructure Network (NNIN), which is supported by NSF award no. ECS-0335765.

\section{References}

1. Zhefeng Li, Roy G. Gordon, Huazhi Li, Deo V. Shenai, and Christian Lavoie, Journal of The Electrochemical Society, 157(6), H679 (2010).
2. H. Nakano, T. Itabashi, and H. Akahoshi, Journal of The Electrochemical Society, 152(3), C163 (2005)

3. Zhengwen Li, Roy G. Gordon, Damon B. Farmer, Youbo Lin, and Joost Vlassak, Electrochemical and Solid-State Letters, 8(7), G182 (2005).

4. M. Kisielewski, A. Maziewski, M. Tekielak, A. Wawro, and L. T. Baczewski, Physical Review Letters, 89(8), 087203 (2002).

5. Nan Li, Xiaoming Wang, Salim Derrouiche, Gary L. Haller, and Lisa D. Pfefferle, ACS Nano, 4(3), 1759 (2010)

6. Hoon Kim, Harish B. Bhandari, Sheng Xu, and Roy G. Gordon, Journal of The Electrochemical Society, 155(7), H496 (2008).

7. Srinivas Gandikota, Steve Voss, Rong Tao, Alain Duboust, Dennis Cong, Liang-Yuh Chen, Sesh Ramaswami, and Daniel Carl, Microelectronic Engineering, 50(1-4), 547 (2000).

8. Zhengwen Li, Antti Rahtu, and Roy G. Gordon, J. Electrochem. Soc., 153(11), C787 (2006).

9. Yeung Au, Youbo Lin, and Roy G. Gordon, J. Electrochem. Soc., 158, D248 (2011).

10. Oh-Kyum Kwon, Se-Hun Kwon, Hyoung-Sang Park, and Sang-Won Kang, Journal of The Electrochemical Society, 151(12), C753 (2004).

11. M. Damayanti, T. Sritharan, Z. H. Gan, S. G. Mhaisalkar, N. Jiang, and L. Chan, Journal of The Electrochemical Society, 153(6), J41 (2006).

12. Seung-Eun Nam and Kew-Ho Lee, Journal of Membrane Science, 192(1-2), 177 (2001).

13. M. Lane, C. Murray, F. McFeely, P. Vereecken, and R. Rosenberg, Applied Physics Letters, 83(12), 2330 (2003).

14. D. Josell, J. E. Bonevich, T. P. Moffat, T. Aaltonen, M. Ritala, and M. Leskela, Electrochemical and Solid-State Letters, 9(2), C48 (2006).

15. A. E. Kaloyeros and E. Eisenbraun, Annual Review of Materials Science, 30(1), 363 (2000).

16. D. Josell, C. Witt, and T. P. Moffat, Electrochemical and Solid-State Letters, 9(2), C41 (2006).

17. Zhengwen Li, Roy G. Gordon, Damon B. Farmer, Youbo Lin, and Joost Vlassak, Electrochem. Solid-State Lett., 8(7), G182 (2005).

18. Hoon Kim, Toshihiko Koseki, Takayuki Ohba, Tomohiro Ohta, Yasuhiko Kojima, Hiroshi Sato, and Yukihiro Shimogaki, Journal of The Electrochemical Society, 152(8), G594 (2005).

19. S. Q. Wang and H. Q. Ye, Current Opinion in Solid State and Materials Science, 10(1), 26 (2006)

20. Qing Min Wang, Jean-Sebastien Lehn, Huazhi Li, Deo Shenai, Jing Yang, and Roy Gordon, Proc. AVS Atomic Layer Deposition Conference, (2011).

21. Zhengwen Li, Don Kuen Lee, Michael Coulter, Leonard N. J. Rodriguez, and Roy G. Gordon, Dalton Trans., (19), 2592 (2008).

22. J. A. Davies, T. E. Jackman, H. L. Eschbach, W. Dobma, U. Wätjen, and D. Chivers, Nuclear Instruments and Methods in Physics Research Section B: Beam Interactions with Materials and Atoms, 15(1-6), 238 (1986).

23. J. J. Vlassak, Y. Lin, T. Y. Tsui, and A. J. McKerro, Materials Research Society Symposia Proceedings, 795 (2004).

24. Z. G. Xiao, Rev. Sci. Instrum., 74(8), 3879 (2003).

25. A. Yanguas-Gil, Y. Yang, N. Kumar, and J. R. Abelson, J. Vac. Sci. Technol. A, 27(5), 1235 (2009).

26. Hui Jia, Xin Wang, Weitao Zheng, Yan Chen, and Shouhua Feng, Materials Science and Engineering: B, 150(2), 121 (2008).

27. S. F. Matar, A. Houari, and M. A. Belkhir, Physical Review B, 75(24), 245109 (2007).

28. L. Peters, Semiconductor International, (2001). 